\title{
Radiological aspects of retroperitoneal fibrosis
}

\author{
Mzabi A $A^{1}$, Marrakchi W' ${ }^{1}$, Alaya $Z^{2 *}$, Rezgui $A^{1}$, Ben Fredj $F^{1}$, Bouajina $E^{2}$ and Laouani $C^{1}$ \\ ${ }^{1}$ Department of Internal Medicine, Sahloul Hospital, Faculty of Medicine of Sousse, Sousse, Tunisia \\ ${ }^{2}$ Department of Rheumatology, Farhat Hached Hospital, Faculty of Medicine of Sousse, Sousse, Tunisia
}

\begin{abstract}
Objective: Evaluate radiological findings on retroperitoneal fibrosis.

Patients and methods : A retrospective analysis conducted in the internal Medicine Department in Sahloul teaching Hospital between 1999 and 2016.

Results: Thirty-two patients were included. There were 24 men and 8 women with a mean age of 58 years. Lower back pain is the most common symptom. Ultrasound showed a dilatation of the urinary cavities $(\mathrm{n}=16,50 \%)$ and the CT scan confirmed the bilateral ureteral catheterization $(\mathrm{n}=11)$. A fibrous mass that surrounds abdominal aorta, the inferior vena cava and the iliac vessels was noted in CT scan (23 cases), in MRI (9 cases). Intravenous urography (IVU) noted ureteropelicillal dilation in 4 cases. Five patients suffered from RFP associated to pulmonary fibrosis ( $\mathrm{n}=2$ ), sarcoidosis $(\mathrm{n}=1)$, immunoglobulin G4-related disease ( $\mathrm{n}=1$ ), Riedel thyroiditis and orbital pseudo tumor $(\mathrm{n}=1)$.
\end{abstract}

Conclusion: The diagnosis of RPF is based on imaging, which seeks an etiology, an associated disease or a complication. CT-scan is the preferred imaging method. MRI may facilitate assessment of disease extent.

\section{Introduction}

Retropertineal fibrosis (RPF) is a rare fibroblastic inflammatory process. It results on the progressive transformation of retroperitoneal adipose tissue into a retractile fibrous tissue. It compresses ureters and abdominal vasculature [1]. The incidence is more pronounced in men and the peack of frequency is between 40 and 60 years old [2]. Clinical and biological polymorphism causes diagnostic and therapeutic difficulties. However, imaging had a valuable aid in the diagnosis especially by CT scan, MRI and renal PET-Scann.

The objective of our study was to determine the interest of radiological tools in the management of retroperitoneal fibrosis.

\section{Patients et méthodes}

It was a retrospective study which included all patients having RPF. It was conducted in the Internal Medicine Department between 1999 and 2016 in Sousse, Tunisia. Data was collected from medical records. Radiological examinations were interpreted and reviewed by a radiologist at the Sahloul University Hospital.

\section{Data collection}

All patients' demographic criteria were studied including age, gender, comorbidities, presenting symptoms and laboratory findings. Imaging findings were reviewed. Due to the age of some files, modern explorations were practiced only in a limited number. We note the progression of the imaging as they are introduced into the technical platform of our hospital.

For the statistics, we used SPSS version 20 software.

\section{Results}

\section{Demographics}

Between 1999 and 2016, we enrolled 32 patients. It included 24 males $(75 \%)$ and eight females $(25 \%)$ with a mean age 58 years old. Low back pain was the most important symptom (100\%).

Several radiological tools were used to establish the diagnosis of $\mathrm{RPF}$ in our analysis.

\section{Intravenous Urography (IVU)}

UVI was practiced in four patients (12.5\%). It had shown hydronephrosis in all cases

\section{Abdominal ultrasound}

Abdominal ultrasound was done in 20 cases. It was normal in four cases $(20 \%)$ and it had shown ureters sheath in all cases. unilateral ureteral dilation was noted in 12 cases (37.5\%). however, it was bilateral in four cases (12.5\%). Ultrasound imaging showed hydronephrosis in four cases (12.5\%). Anechoic fibrous lesion was noted in three cases (9.4\%). Abdominal aortic anevrysm was detected in two cases $(6.2 \%)$.

Correspondence to: Zeineb Alaya, Department of Rheumatology, Farhat Hached Hospital, Faculty of medicine of Sousse, Ibn el Jazzar Street, 4000 Sousse, Tunisia, Tel: +21698375975; E-mail: zeineb_a@hotmail.fr

Key words: Retroperitoneal fibrosis - Imaging

Received: November 20, 2017; Accepted: January 03, 2018; Published: January 06,2018 


\section{Abdominal CT-scan}

It was practiced in 26 cases (81.2\%). It showed retroperitoneal sleeve with homogenous density and regular contours associated with abdominal vascular sheath in 23 cases (71.8\%) (Figure 1). Peri ureteral lesions were noted in 11 cases $(34.3 \%)$. Thrombosis of the renal vein extended to the inferior vena cava was identified in one patient $(3.1 \%)$. An anevrysm of the abdominal aorta was noted in two cases (6.2\%).

\section{Renal MRI}

Renal MRI was done in eleven cases (34.3\%). It showed vascular sheath in nine cases $(81.8 \%)$. Renal venous thrombosis extended to the inferior vena cava was noted in one case (9\%) (Figure 2).

\section{Radiological aspects of pathologies associated with RPF}

RPF was isolated without any other pathology in 27 cases (84.4\%). Auto-immune pathology associated with RPF was noted in five cases $(15.6 \%)$. It was pulmonary fibrosis in two cases $(40 \%)$. Sarcoidosis and immunoglobulin G4-related were noted in one case each one (10\%). The last patient had Riedel thyroiditis and orbital pseudo-tumor (10\%).

\section{Pulmonary fibrosis}

Pulmonary and mediastinal fibrosis was noted in two patients who were 48 and 54 years old respectively. Diagnosis was made by the CTscan aspects.

\section{Sarcoidosis}

Observation: It was a male patient who had 55 years old. He was treated for cervical adenopathy in the last two years. He had asthenia, loss of weight and bilateral low back pain. Laboratory investigations showed inflammatory biological syndrom. CT-scan had shown retroperitoneal sleeve whith vascular sheath (Figure 3). Histology examination showed

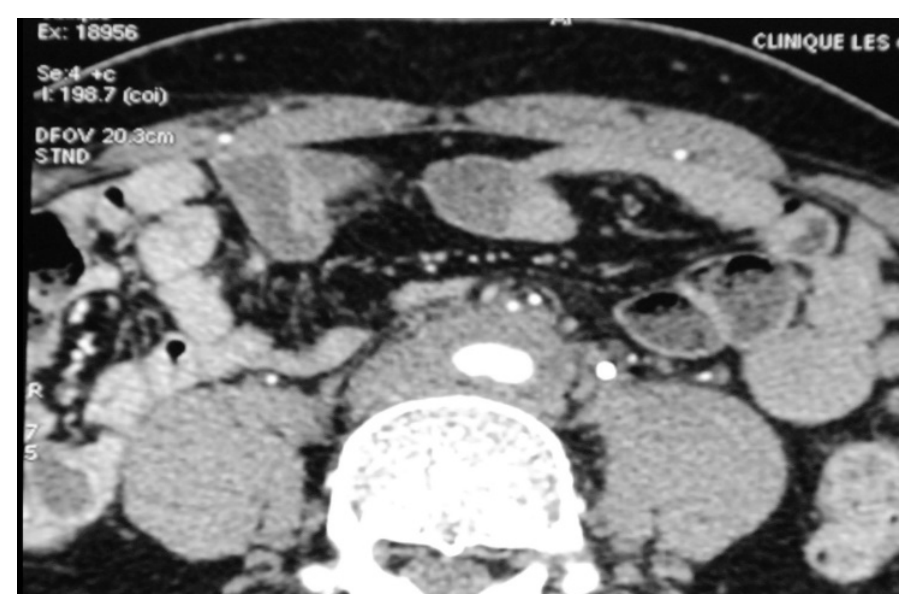

Figure 1. CT-scan showing retroperitoneal and peri aortic sleeve
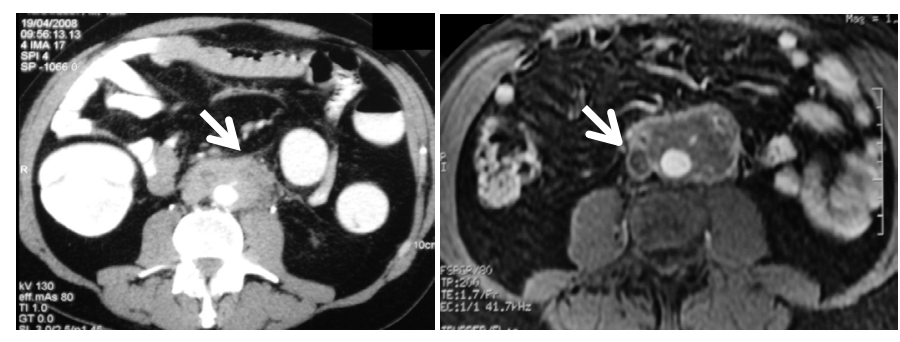

Figure 2. CT scan showing RPF and MRI T1 ponderation showing thrombosis of inferior vena cava (flèche)

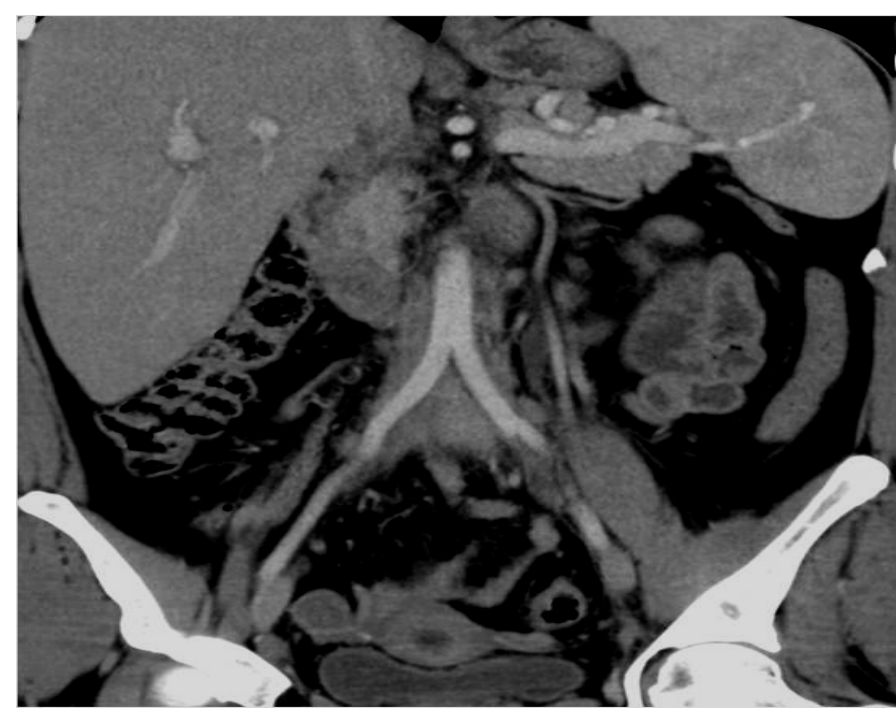

Figure 3. Abdomino-pelvic CT-scan showing RPF whith peri aortic sheath

multiple epitheliod and giganto-cellular granulomas. We started him with corticoisteroids with favourable outcomes.

\section{Riedel throiditis and orbital}

Observation: It was a female patient who had 45 years old. She was treated with Tamoxifene. Then, medical examination found goiter associated with diplopia. CT-scan showed thyroid and mediastinal fibrosis. (Figure 4).

Brain CT-scan showed orbital fibrostic sleeve with orbital pseudotumor (Figure 5).

\section{Hyper IG4 syndrome}

Observation: It was a male patient who was 71 years old with a medical history of diabetes, hypertension and anemia. He consulted for fatigue and asthenia. Abdominal CT-Scan showed peri aortic and peri iliac artery fibrosis. Laboratory investigations showed increased IgG4 $(=1,940 \mathrm{~g} / \mathrm{l})$. we did not complete investigations because the patient refused any other tests.

\section{Discussion}

RPF is a rare inflammatory pathology. It is still mysterious and is requiring further explanation. There are limited available data about RPF in the litterature. Retroperitoneal fibrosis can involve any organ proximate to the retroperitoneum. It is characterized by the fibous involvement of the renal vessels and the ureters causing the urinary excretion impairment [3]. Intestinal or biliary-pancreatic involvement and other pelvic organ and peripheral nerve involvement have all been reported. The clinical presentation includes low back pain, renal failure, anemia and accelerated sedimention rate. [2]. CT-scan and MRI are the most commoly used for diagnosis and the therapeutic follow up [4-6]. Although intravenous urography was the key radiological exploration in previous bibliographic references, it is currently abandoned in favour of more efficient and less invasive explorations [7].

\section{Diagnosis of RPF}

\section{Intravenous Urography}

It includes the usual triad of pyelocaliceal and proximal ureter dilation $(20 \%-70 \%)$, extrinsic compression and medial deviation of the ureters (Figure 6) [8,9]. 


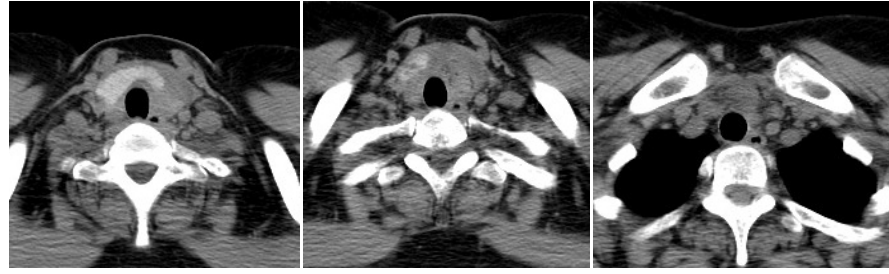

Figure 4. CT-scan showing thyroid firous sleeve associated with mediastinal fibrosis.

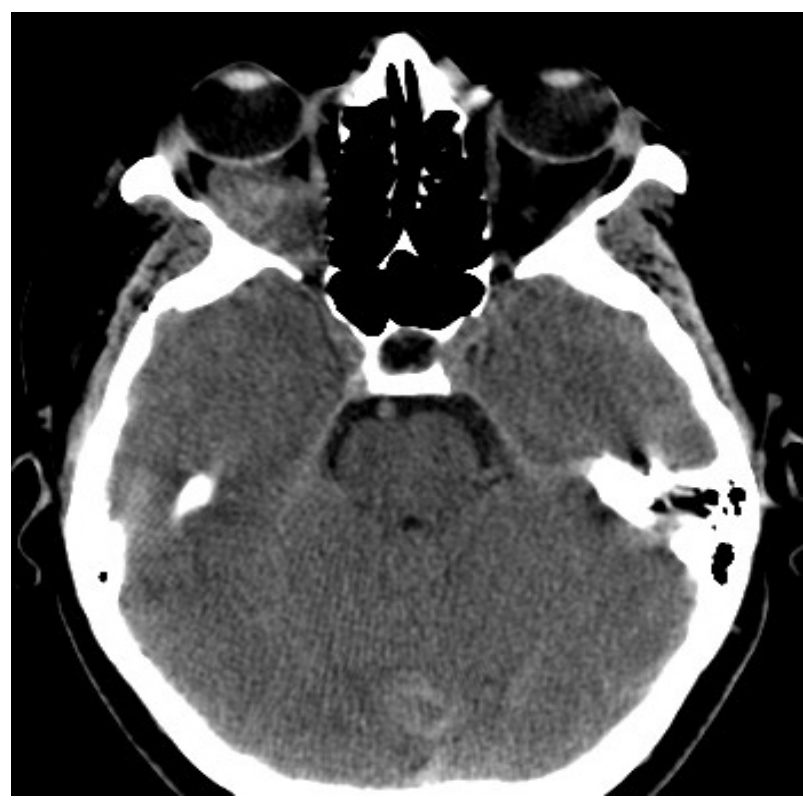

Figure 5. CT-scan showing orbital fibrous tissue

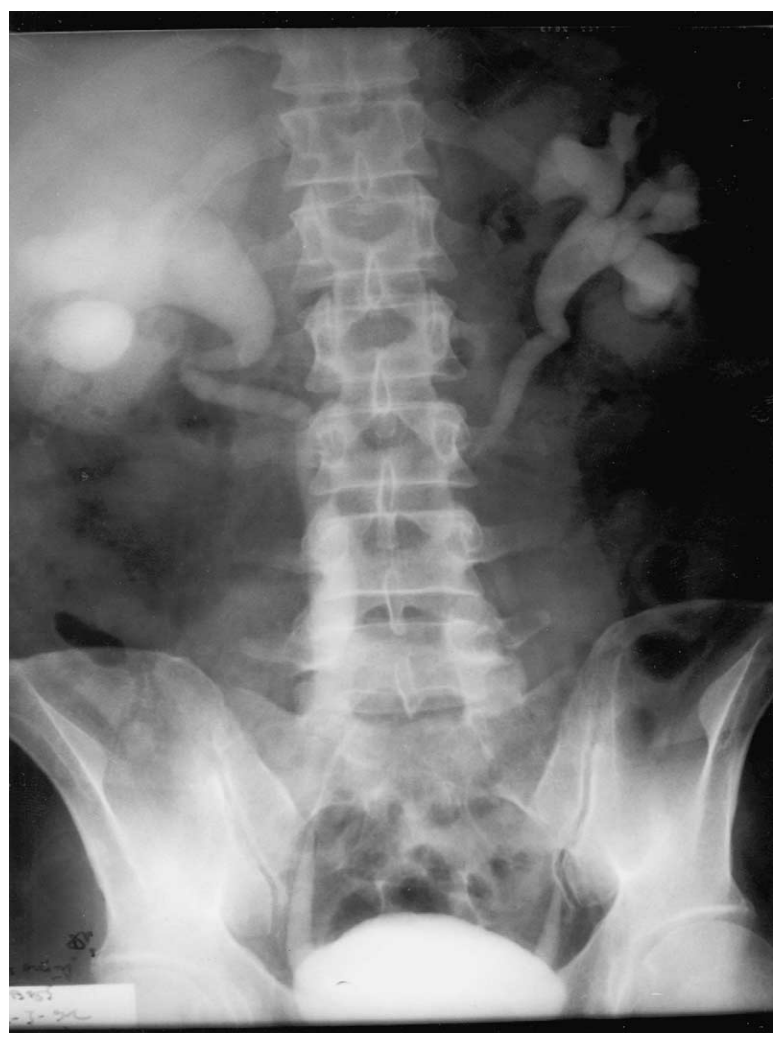

Figure 6. Uretero pyelocaliceal dilation
IVU is abandoned in favour of CT-scan and MRI which offer more detailed and specific information about RPF [10].

It was practiced in four cases and it showed indirect signs of obstruction in all cases.

\section{Abdominal ultrasound imaging}

In some cases, ultrasound reveals a well-defined mass with variable echostructure in close contact with the abdominal vessels [2,11].

It frequently shows a repercussion on the upper urinary tract with hydronephrosis [2,9].

This imaging is no more used in the positive diagnosis of RPF. It makes it possible to suspect the disease without confirming it. Renal doppler ultrasound shows indirect signs of RPF $[10,12,13]$. In our analysis, ultrasound showed ureter sheath associated with dilation in 16 cases $(50 \%)$.

The abdomino-pelvic ultrasound was justified in several patients by the initial symptomatology which was nonspecific and dominated by lumbar pain. It will serve as a descrambling examination and will be supplemented by more sensitive examinations for the RPF.

\section{Abdominal CT-scan}

In our series, the CT performed in 26 patients made the diagnosis in 23 cases in $88 \%$ of the cases. Our results are similar to those of the literature, since CT led to the diagnosis of RPF in $72 \%$ of cases in the Lugosi study [10]. In the Sérézal study [15], the CT confirmed the diagnosis of RPF in $100 \%$ of cases.

Thus, abdominal CT remains the standard imaging method in diagnosis $[14,16]$. it shows a well-delimited fibrous tissue with homogeneous density which is engaging the large vessels and the ureters and enhancing to the injection of contrast in the early stages (Figure 7) [3,17].

A radiological classification recently proposed by Scheel [18] is available in some published studies [15]. This classification involves distributing lesions of fibrosis as follows:

Classe I: aortic and iliac artery location;

- Classe II: inferior vena cava involvement;

- Classe III: lateral extension to the ureter;

- Classe IV: Extension to the renal hilum with involvement of the renal artery or the renal vein.

\section{Renal MRI}

MRI offers more advantages than CT-scan. It analyses of the characteristics of the peri-aortic fibrous sleeve and its anatomical ratios (Figure 8).

It also allows the acquisition in many planes. The injection of contrast agent based on gadolinium is significantly less nephrotoxic than the iodine product for used for CT [2]. Finally, MRI helps to differentiate between malignant RPF and non-tumoral forms [16]. This technique allows the diagnosis, the assessment of obstructive complications and the follow-up of RPF [10].

In our study, it showed RPF in $82 \%$ of cases.

\section{PET- scann (Figure 9) [19]}

This imaging seems to be useful in the initial review of the RPF [10]. 


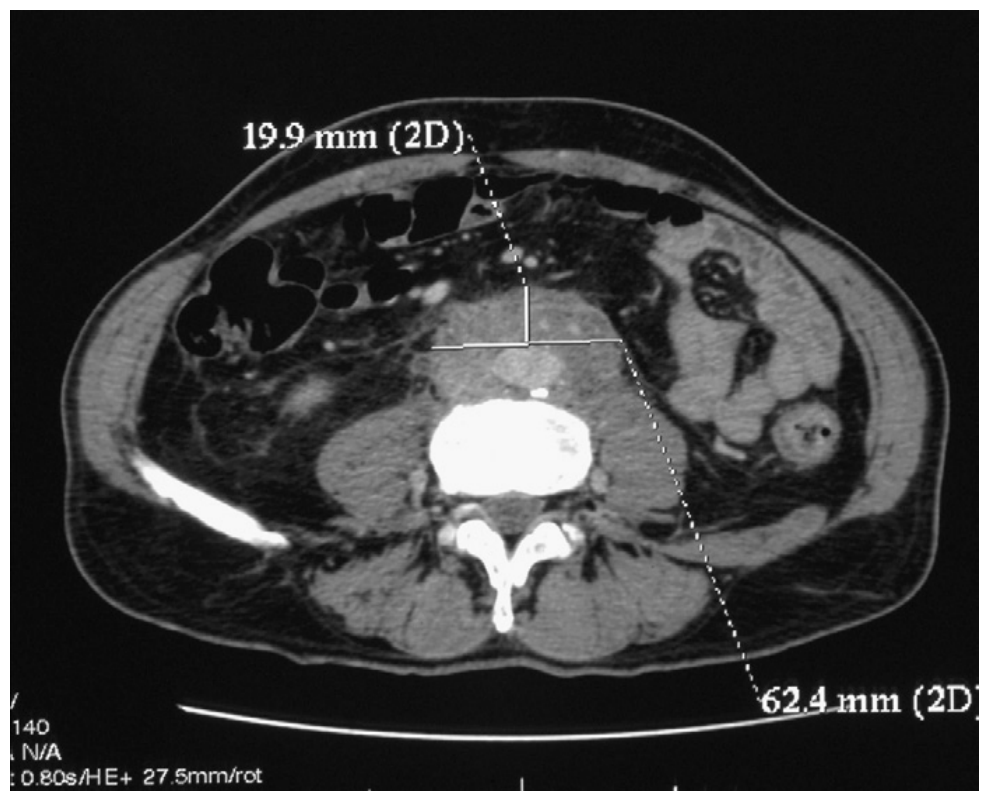

Figure 7. CT-scan showing fibrous lesion with vascular involvement

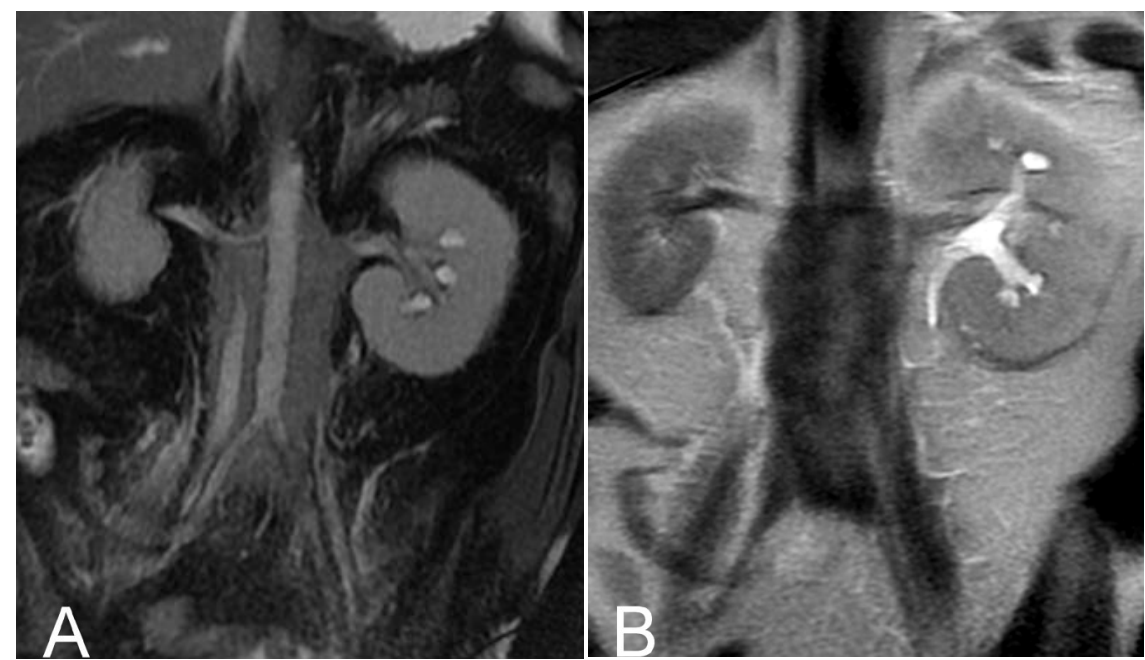

Figure 8. Abdominal MRI perivascular and retroperitoneal lesion in hyposignal T2(A) ureteral involvement (B).

Although fixation does not systematically shows morphological data visualized by CT scan and MRI, PET scan assesses the extension of RPF, the vascular and the perivascular lesions [20,21].

It could also help in the monitoring of the RPF [21]. In the study of Serezal [15], this technique was performed in 11 patients, at different stages of the evolution of the RPF. Retroperitoneal lesions were then fixed in 8 cases out of $11(72.7 \%)$.

Moreover, in the Desbois study [22], nine DFG-TEP-CT were performed, showing discrete hypermetabolic foci in six cases (66.6\%). The PET scanner can be used for the detection of multifocal fibrosis lesions when an inflammatory disease is associated with RPF [23]. It also has an interest in the follow up of the disease during corticosteroid therapy [24].

\section{Renal scintigraphy with 2,3-dimercaptosuccinic acid (DMSA)}

It can be proposed to evaluate the function of each [24]. Renal scintigraphy provides a complementary functional element to the
Table 1. Medical Interest of Imaging [24]

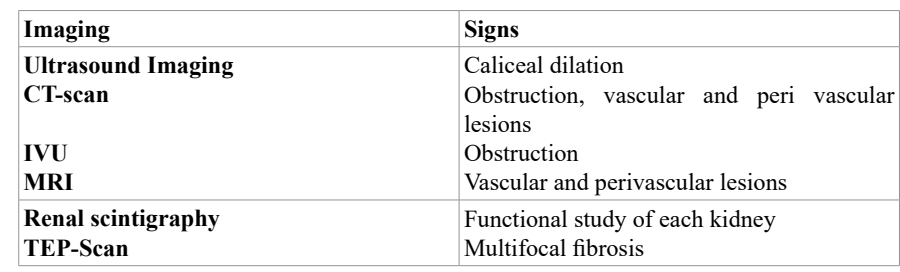

etiological analysis of renal insufficiency during the RPF [25]. No renal scintigraphy was requested in our study (Table 1).

\section{Diagnosis of illness associated with RPF}

FRP may be isolated or associated with systemic diseases (Table 2) $[2,26,27-29]$. Many publications report associations with multiple diseases whose substratum can be immunological or inflammatory.

In the Lugosi study [10], RPF was associated with systemic vasculitis in three cases: granulomatosis with polyangiitis $(n=1)$ and 


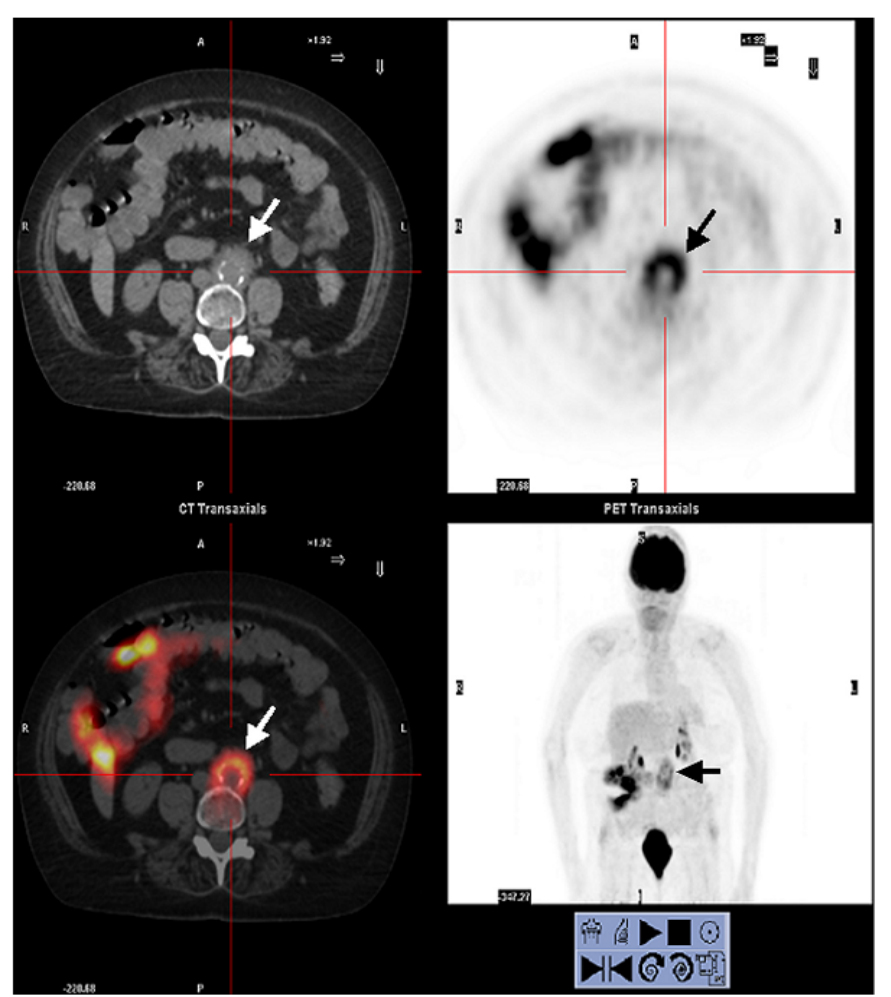

Figure 9. PET scan. Intense fixation of the tracer (arrows) characterizing the perioraortic retroperitoneal fibrosis which is extended between L3 and L5 and including the aorto-iliac intersection

Table 2. RPF associated pathologies [2]

\begin{tabular}{|c|c|}
\hline Fibrosing diseases & $\begin{array}{l}\text { Orbital pseudo Tumor } \\
\text { Riedel thyroiditis } \\
\text { Sclerosing cholangitis } \\
\text { Pulmonary fibrosis } \\
\text { Pancreatic pseudo-Tumor }\end{array}$ \\
\hline vasculitis & $\begin{array}{l}\text { Necrotizing peri-arteritis } \\
\text { Horton's Disease } \\
\text { Takayasu's ateritis } \\
\text { Scleroderma } \\
\text { Systemic lupus } \\
\text { Spondylarthritis }\end{array}$ \\
\hline granulomatosis & $\begin{array}{l}\text { Sarcoidosis } \\
\text { Primary biliary cirrhosis }\end{array}$ \\
\hline Other diseases & $\begin{array}{l}\text { Sickle cell disease } \\
\text { Uveitis } \\
\text { Cryoglobulinemia }\end{array}$ \\
\hline
\end{tabular}

Takayasu's disease $(n=2)$. Riedel's thyroiditis was associated with RPF in one case . In the study of Ouertani [13], FRP was associated with systemic vasculitis in 2 cases: granulomatosis with polyangiitis and Takayasu's disease in one case each one. In our study, FRP was associated pulmonary fibrosis ( 2 cases), sarcoidosis ( 1 case), Riedel's thyroiditis and an orbital pseudotumor (1 case) and hyper-IgG4 syndrome in the latter case.

\section{Conclusion}

RPFremains a rare inflammatory disease. Its pathogenesis is still poorly understood. Clinical signs and symptoms are not very specific. The biological assessment is essential but often not very useful for the diagnosis. The radiological assessment helps to demonstrate the fibrous lesion, to evaluate its extension and its renal repercussion and finally to orient the biopsies for the positive diagnosis.

\section{References}

1. Gilkeson GS, Allen NB (1996) Retroperitoneal fibrosis. A true connective tissue disease. Rheum Dis Clin North Am 22: 23-38. [Crossref]

2. Meier P, Gilabert C, Burnier M, Blanc E (2003) La fibrose rétropéritonéale, une maladie inflammatoire méconnue. Observations cliniques et revue de la littérature. Nephrologie 24: 173-180.

3. Vaglio A, Salvarani C, Buzio C (2006) Retroperitoneal fibrosis. Lancet 367: 241-251. [Crossref]

4. Vaglio A, Corradi D, Manenti L, Ferretti S, Garini G, et al. (2003) Evidence of autoimmunity in chronic periaortitis: a prospective study. Am J Med 114: 454-462. [Crossref]

5. Van Bommel EF, Jansen I, Hendriksz TR, Aarnoudse AL (2009) Idiopathic retroperitoneal fibrosis: prospective evaluation of incidence and clinicoradiologic presentation. Medicine (Baltimore) 88: 193-201.

6. Vaglio A, Palmisano A, Alberici F, Maggiore U, Ferretti S, et al. (2011) Prednisone versus tamoxifen in patients with idiopathic retroperitoneal fibrosis: an open-label randomised controlled trial. Lancet 378: 338-346. [Crossref]

7. Niccoli Asabella A, Nicoletti A, Altini C, Notaristefano A, Lastilla G, et al. (2013) 18F-FDG Positron Emission Tomography/Computed Tomography in the Diagnosis and Post-Therapeutic Treatment in a Patient with an Early Stage of Retroperitoneal Fibrosis. Mol Imaging Radionucl Ther 22: 60-62. [Crossref]

8. Minford JE, Davies P (1984) The urographic appearances in acute and chronic retroperitoneal fibrosis. Clin Radiol 35: 51-57. [Crossref]

9. Benchekroun A, Jira H, Kasmaoui el H, Nouini Y, Iken A, et al. (2002) [Retroperitoneal fibrosis. Report of 6 cases]. Ann Urol (Paris) 36: 171-175. [Crossref]

10. Lugosi M, Sacré K, Lidove O, Chauveheid MP, Brihaye B, et al. (2013) [Long-term follow-up of a French cohort of retroperitoneal fibrosis]. Rev Med Interne 34: 591-599. [Crossref]

11. Blanc G, Girard N, Alexandre C, Vignon E (2007) Retroperitoneal fibrosis: a rare vascular and immune entity disclosed by chronic lombalgia. Joint Bone Spine 74: 497 499. [Crossref] 
12. Fibrose rétropéritonéale: une maladie vasculaire ou immunitaire responsable de lombalgie. Retroperitoneal fibrosis: a rare vascular and immune entity disclosed by chronic lombalgia. Revue du Rhumatisme 2007; 74: 902 - 904.

13. Tarantino L, Giorgio A, De Stefano G, Esposito F (2000) [Idiopathic retroperitoneal fibrosis diagnosed with color Doppler echography and ultrasonography-guided fine needle biopsy, a case report]. Radiol Med 100: 387-389. [Crossref]

14. Ouertani D, Smiti Khanfir M, Klaii R, Braham A, Larbi T, et al. (2009) La fibrose rétropéritonéale. À propos de huit cas. La Revue de médecine interne 30 : S77-S151.

15. Mulligan SA, Holley HC, Koehler RE, Koslin DB, Rubin E, et al. (1989) CT and MR imaging in the evaluation of retroperitoneal fibrosis. J Comput Assist Tomogr 13: 277 281. [Crossref]

16. Gallais Sérézal I1, Le Jeune S2, Belenfant X3, Bakir R4, Fain O5, et al. (2014) [Idiopathic retroperitoneal fibrosis: a multicentric retrospective study of 30 French cases and follow-up of the renal function]. Rev Med Interne 35: 570-576. [Crossref]

17. Triantopoulou C1, Rizos S, Bourli A, Koulentianos E, Dervenis C (2002) Localized unilateral perirenal fibrosis: CT and MRI appearances. Eur Radiol 12: 2743-2746. [Crossref]

18. Vivas I, Nicolás AI, Velázquez P, Elduayen B, Fernández-Villa T, et al. (2000) Retroperitoneal fibrosis: typical and atypical manifestations. Br J Radiol 73: 214-222. [Crossref]

19. Scheel PJ Jr, Feeley N (2009) Retroperitoneal fibrosis: the clinical, laboratory, and radiographic presentation. Medicine (Baltimore) 88: 202-207. [Crossref]

20. Gaertner S, Cordeanu EM, Mirea C, Stephan D (2014) [Retroperitoneal fibrosis]. Presse Med 43: 1021-1023. [Crossref]
21. Vaglio A, Versari A, Fraternali A, Ferrozzi F, Salvarani C, et al. (2005) (18) F-fluorodeoxyglucose positron emission tomography in the diagnosis and followup of idiopathic retroperitoneal fibrosis. Arthritis Rheum 53: 122-125. [Crossref]

22. Moroni G, Castellani M, Balzani A, Dore R, Bonelli N, et al. (2012) The value of (18) F-FDG PET/CT in the assessment of active idiopathic retroperitoneal fibrosis. Eur $J$ Nucl Med Mol Imaging 39: 1635-1642. [Crossref]

23. Desbois AC, Hervier B, Haroche J, Lucidarme O, Wechsler B, Charlotte F, et al. (2010) Fibrose rétropéritonéale " idiopathique " : à propos de 31 cas La Revue de médecine interne 31S (2010) S35-S83

24. Drieskens O, Blockmans D, Van den Bruel A, Mortelmans L (2002) Riedel's thyroiditis and retroperitoneal fibrosis in multifocal fibrosclerosis: positron emission tomographic findings. Clin Nucl Med 27: 413-415. [Crossref]

25. Estrade V, Traxer O, Sibony M, Haab F (2004) [Retroperitoneal fibrosis]. Ann Urol (Paris) 38: 3-13. [Crossref]

26. Kukuk S, Krestschmer A, Bruck H, Roth S, Brandt AS (2015) Retroperitoneal fibrosis: Development of a biomarker profile for diagnosis and therapy monitoring. Urologe $A$ 54: 52-61. [Crossref]

27. Ahsan N, Choudhury AA, Berger A (1990) Retroperitoneal fibrosis. Am Fam Physician 41: 1775-1780. [Crossref]

28. Klisnick A, Fourcade J, Ruivard M, Baud O, Souweine B, et al. (1999) Combined idiopathic retroperitoneal and mediastinal fibrosis with pericardial involvement. Clin Nephrol 52: 51-55. [Crossref]

29. Chauveau D, Fiquet-Kempf B, Mejean A, et al. (1997) Fibrose rétropéritonéale: faits cliniques et physiopathologiques récents. Séminaires d'uronéphrologie. Paris: Flammarion Médecine-Science 226-234.

Copyright: (C2018 Mzabi A . This is an open-access article distributed under the terms of the Creative Commons Attribution License, which permits unrestricted use, distribution, and reproduction in any medium, provided the original author and source are credited. 